\title{
Identification of hijaiyah letters using wirelessly controlled arabic braille module
}

\author{
Nik Azimah Zainab Nik Mohd Rahimi ${ }^{1}$, Noor Hazrin Hany Mohamad Hanif ${ }^{2}$, Zuriati Janin ${ }^{3}$ \\ ${ }^{1,2}$ Department of Mechatronics Enginering, International Islamic University Malaysia (IIUM), Malaysia \\ ${ }^{3}$ Universiti Teknologi MARA (UiTM), Malaysia
}

\begin{tabular}{l}
\hline \hline Article Info \\
\hline Article history: \\
Received Jun 8, 2019 \\
Revised Aug 10, 2019 \\
Accepted Aug 24, 2019 \\
\hline
\end{tabular}

Keywords:

Arabic braille

Hijaiyah letters

Self-learn

Visually impaired

\begin{abstract}
Among the major issues faced by the visually impaired people is the inability to read, and this is could be addressed by learning braille. However the scarcity of skilled instructors to teach the braille codes to the visually impaired people limits the learning process. This paper presents a psychophysical study on the ability of people with visual challenges to identify hijaiyah letters from a specially developed Arabic braille module. This module consists of six miniature solenoids that are wirelessly controlled via a Bluetooth and an Arduino Uno microcontroller. Five different hijaiyah letters were provided to the participants and were randomly repeated for three times. The participants were required to touch the Arabic braille module and state the hijaiyah letters that were displayed. With priori knowledge and initial familiarization of the braille patterns, $72.9 \%$ of the trials showed accuracy between the braille display and the stated hijaiyah letters. $20 \%$ of the participants have the highest repeatability responses of $80 \%$. The outcome of this work showed the optimistic capability of the wirelessly controlled Arabic braille display to assist visually impaired individual to read hijaiyah braille letters and ultimately promotes independence in learning.
\end{abstract}

Copyright $\odot 2020$ Institute of Advanced Engineering and Science. All rights reserved.

\section{Corresponding Author:}

Noor Hazrin Hany Mohamad Hanif,

Department of Mechatronics Engineering,

Internation Islamic University Malaysia, Malaysia.

Email: noorhazrin@iium.edu.my

\section{INTRODUCTION}

According the World Health Organization (WHO) report in October 2018, approximately 1.3 billion of world's populations live with some form of vision impairment [1]. With regards to distance vision, 405.5 million people have mild to severe vision impairment (visual acuity worse than 6/60), and 36 million people are blind (visual acuity worse than 3/60) [2].

Unfortunately, approximately $20 \%$ of vision impairment globally is considered unavoidable. Thus vision rehabilitation is sought after in improving the quality of life of people with irreversible vision impairment [3]. Various vision aid ranging from mobility aids [4, 5] to reading aids via 'text-to-speech' technology [6], are widely available in the market and have proven its usefulness. However, total dependency on audio technologies for reading, lead to a high illiteracy rate amongst people with visual disabilities. Works by Fields revealed that by reading, or learning to read, the structural changes in human brain tissues evolves, which suggests higher brain development for people who are literate [7].

A way to address this illiteracy is by encouraging the visually impaired people to read and write using their tactile senses. Visually impaired person are able to detect tactile information faster than people with normal vision [8]. Furthermore, people are able to distinguish the different roughness of a material with $5 \mu \mathrm{m}$ particles and $9 \mu \mathrm{m}$ particles just by sliding their fingertips on any material [9]. Thus a visually impaired 
person can 'read' by using braille system, which consists of six raised dots arranged in 3-by-2 matrix that has a maximum combination of 64 patterns including alphabets, numbers and special characters [10, 11].

The fabrication cost of a 'book' with braille characters are however, considerably costly. An AlQuran braille, for example, may cost more than MYR 400 per copy, which is quite a burden for the visually impaired person to own one [12]. Recent advances have provided braille users with refreshable braille displays that enable users to reuse the braille system as different reading materials. A 'Tactobook' by Velázquez, for example, demonstrates the capability of a piezoelectric tactile terminal for braille readers by translating electronic books to braille code and reproduce them in portable electronic braille terminal using the piezoelectric braille cells $[13,14]$.

Learning and teaching braille could pose a big challenge for a developing country as methods and resources are limited and might be very costly and resulting in low literacy rate among the visually impaired people [15]. The conventional system of teaching braille required a large number of skilled tutor to perform one-to-one, tutor-student and demanded a significant amount of time to learn braille [16]. Eventhough the teaching process is aided by a tool called 'brailler', most of the braillers available in market are only catered for languages that utilize Roman characters. Hence, learning other braille code languages with different alphabets system are challenging for the visually impaired people particularly [17, 18]. For instance, the official language of Malaysia, Bahasa Malaysia, can be written in Roman alphabets (also commonly known as 'Rumi') as well as in Hijaiyah letters (commonly known as 'Jawi'). In this project, a new refreshable braille display was developed to facilitate the teaching and learning of the Hijaiyah letters (or Arabic letters) that could specifically facilitate Malaysian users to read 'Jawi' braille codes.

Various researches have been conducted to expose hijaiyah braille to users, including utilization of portable keyboard and microcontrollers to differentiate input characters, brailler display via audio recognition as well as translation of the holy Quran and its tajwid (recitation rule) into braille codes [19-21]. Factors such as works in real-time, light in weight, compact and portable for the consumer to use anywhere were considered important [22-24] and were adapted into all these braille modules. Further upgrades on Braille modules include wireless controlled Braille device via semiconductor and Bluetooth communications [2, 8]. By going wireless, the braille device becomes less bulky and portable; however the current braille devices with wireless technology utilize non-common software which makes it less appealing. This has thus become one of the motivations of our research work.

In our previous work, we developed a mobile application to control the braille display of hijaiyah letters. The compact sized Arabic braille module was designed using miniature solenoids with Arduino Uno as microcontroller, with the aid of a Bluetooth module (HC-06) and open sourced mobile applications. The complete set-up of the Arabic braille module is as shown in Figure 1. By programming the braille display to an android based smartphone, the instructor selects any Arabic letter, in which the input is passed to the Arduino microcontroller via a Bluetooth module. The microcontroller will next actuate the braille code of the module based on the selected alphabet at the teaching panel. Initial tests with six LEDs to represent the miniature solenoids showed that the mobile applications, powered by a Bluetooth module, accurately capable to represent raised dots of braille display [25].

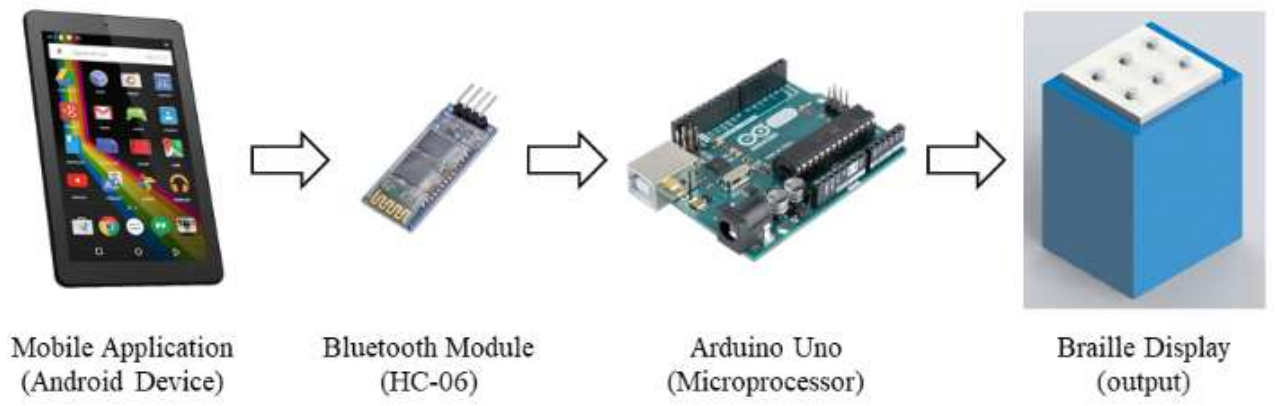

Figure 1. The complete set-up of arabic braille module

In this paper, we highlight users' responses when utilizing the wirelessly controlled braille device. Participants were required to touch and feel the patterns of the braille codes using their fingertip without looking at the braille module and identify associated hijaiyah letters with the Arabic braille character provided on a piece of paper. 


\section{RESEARCH METHOD}

This research work was divided into parts, which are hardware configurations as well as psychophysical investigations. The hardware configurations include the configuration of braille module circuits and integration between the mobile applications and braille output from the miniature solenoids. The psychophysical investigations highlight the responses obtained from healthy participants in identifying the hijaiyah letters when touching the braille modules.

\subsection{Hardware Configurations}

Six DC solenoid valves were used as a mechanical actuator to actuate the braille module and operated on $5 \mathrm{Vdc}-12 \mathrm{Vdc}$ power supply. The solenoid has two end sides; one side of the solenoid was connected to $5 \mathrm{~V}$ of power supply while the other one connected to the collector of TIP120 transistor. The TIP120 transistor is used when Arduino is required to control high power components because Arduino can only control at most of $5 \mathrm{Vdc}$ of component at a time. Thus, implementing the transistor in this circuitry will allow the Arduino to control the $5 \mathrm{Vdc}$ solenoid of the braille module.

Transistor was set up as a switch when the Arduino sends a high signal to the base leg of the transistor, current flowed from collector to emitter will produce a push-up response of the solenoid. A $220 \Omega$ resistor was placed in the middle of Arduino and transistor connection to prevent short circuit. Lastly, the emitter was connected to the ground of the circuit. The circuit was powered up using $7.4 \mathrm{~V}$ battery.

The complete braille display module as shown in Figure 2 is made up from a printed circuit board (PCB), a 3D-print frame and six solenoids actuator. The total of 27 basic Arabic has distinct Arabic braille code and was programmed using Arduino software. The arrangement of the solenoids was in 3 by 2 matrix resembled the braille code writing system and connected to different pin of the Arduino. The Arduino sends a high input signal " 1 " and a low input signal " 0 " to represent the "ON" and "OFF" of the solenoids respectively.

Only five characters; I (alif), خ (khaa), ض (dhod), في (faa) and were tested in the psychophysical test. The characters are as shown in Table 1. The mobile application controlled the braille display through Bluetooth communication. The input signal from the Bluetooth module and the output signal from the Arduino had been discussed in [8]. Each character is represented by different set of high and low output signals. For example, the Arduino execute an output signal of 1, 0, 0, 0, 0, 0 to pin A, B, C, D, E and F respectively when the Bluetooth module sent the number "10" representing I (alif).

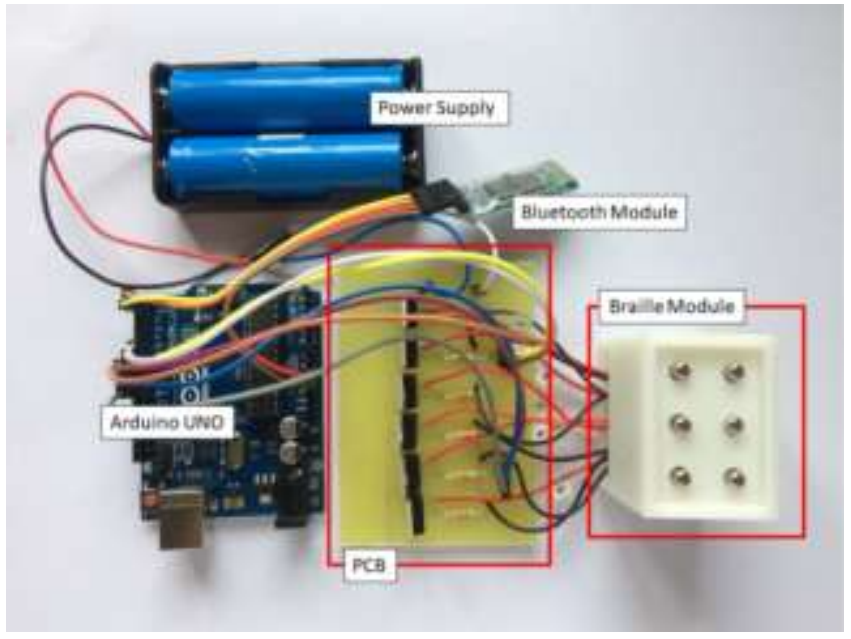

Figure 2. Components of braille module system
Table 1. Five Braille Code for Psychophysical Test

\begin{tabular}{|c|c|}
\hline \multirow[t]{8}{*}{ Braille Code } & Alphabet \\
\hline & 1 \\
\hline & Alif \\
\hline & ئي \\
\hline & $\underset{\text { Khaa }}{\dot{\tau}}$ \\
\hline & ف \\
\hline & Faa \\
\hline & $\begin{array}{c}\text { Dhod } \\
\text { Dhod }\end{array}$ \\
\hline
\end{tabular}

\subsection{Psychophysical Investigations}

The psychophysical test was conducted on 10 healthy subjects ( 7 female and 3 male students) from Mechatronics Department of International Islamic University (IIUM) with an average age of 23. All subjects were medically stable and did not have any history of upper motor neuron condition. The subjects were capable to distinguish the up and down pattern of solenoid using stimuli at the fingertip. Pacemaker users and mental disorders people were excluded to undergo this psychophysical test because it might affect the accuracy of data collection. 
The subject was requested to sit at rest with braille module on table at chest level like reading or writing position, as shown in Figure 3. The braille module was set in a box with a window at one side for the subject to place hand on the braille module. The braille module system was connected wirelessly with the teaching panel through Bluetooth. The teaching panel was placed opposite to the braille module so that it was hidden from subject's vision to replicate the condition of visual impair for all healthy subjects.

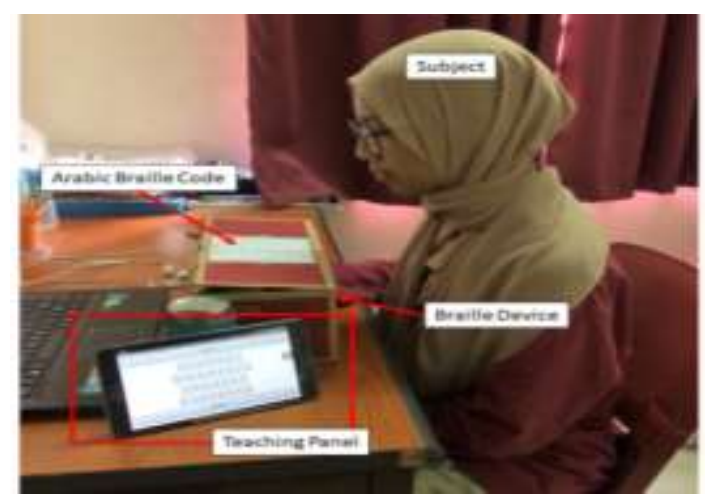

Figure 3. Positions of the braille device, teaching panel and Arabic braille code during the psychophysical test

The subjects were divided into two groups, Group A and Group B with 5 persons per each group. The braille code of the tested Arabic character was introduced to the subjects from group A before the experiment was conducted and 100 seconds was given for familiarization of the pattern. Group B on the hand, was tested without prior knowledge on braille pattern. During experiment, each of the character was displayed for 20 seconds before the braille module was reset to default mode and the subjects need to identify the character within the time limit. The tested-braille code character was pasted on top of the box to facilitate the subjects with no prior in detecting the braille code.

\section{RESULTS AND ANALYSIS}

The aim of this psychophysical test was to evaluate the effectiveness and performances of the device by measure the precise detection of braille code by the subjects. The sample data for each group was 75 samples ( 5 hijaiyah letters x 3 repetitions x 5 subjects). The total data sample collected was 150 for both Group A and Group B. Figure 4 shows the overall number of subjects that succeeded to detect the hijaiyah letters correctly based on trials of each group.

The average total correct answer for Arabic braille code from Group A who had the prior knowledge on braille code was $72.9 \%$ (54 correct identification out of 75 samples) and $58.7 \%$ correct identification (44 correct response out of 75 samples) for Group B. When combined, the percentage of correct identification was $65.3 \%$.

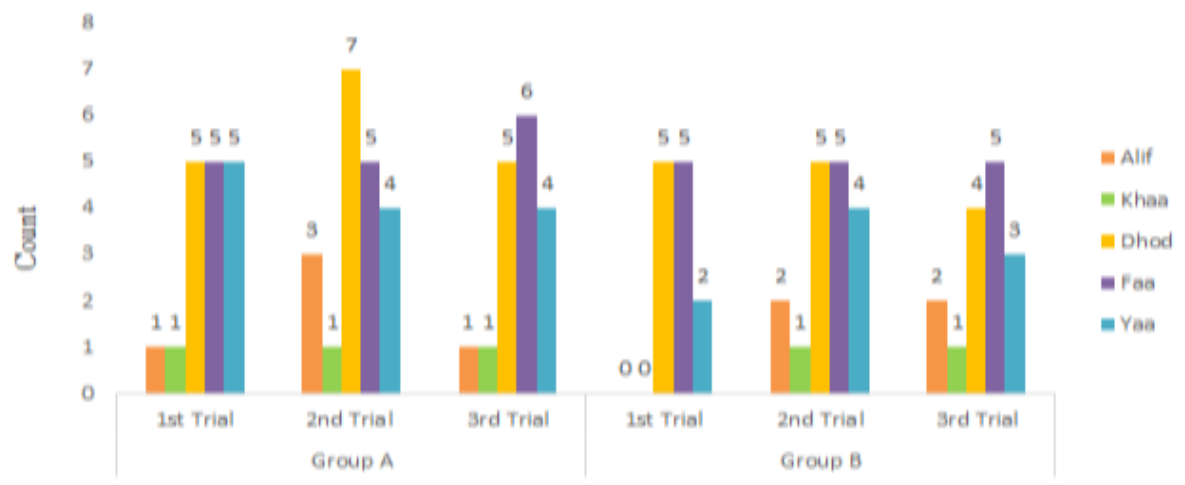

Figure 4. Histogram of correctly identified hijaiyah letters for a given braille input 
A further analysis was done to observe individual responses when using the braille module. As shown in Figure 5, two persons from Group A scored the highest percentage of $80 \%$ (12 out of 15 trials) for correct identification. For Group B, three persons managed to obtain the highest percentage of correct identification of $67 \%$ (10 out of 15 trials). It could be deduced that although the subjects from Group A had familiarized with the braille module and perceived basic braille code knowledge beforehand, the advantage did not significantly affect the identification result. The response from Group B proved that a 'new learner' can also master the braille code too without prior knowledge. Thus, this Arabic braille module was relevant for a new comer to learn hijaiyah braille alphabets because of clear and simple device system.

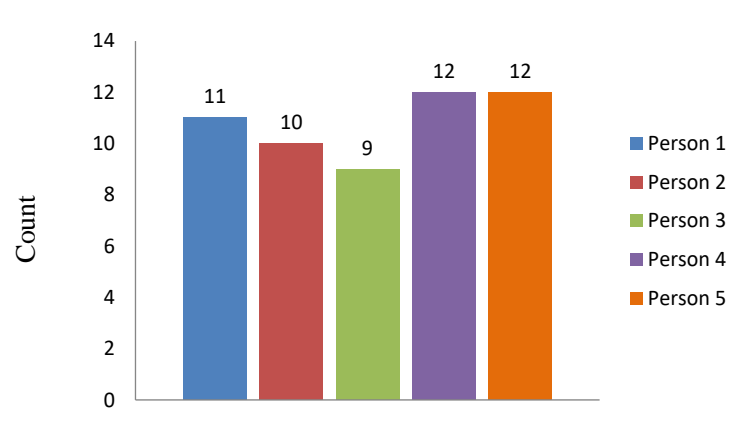

Group A

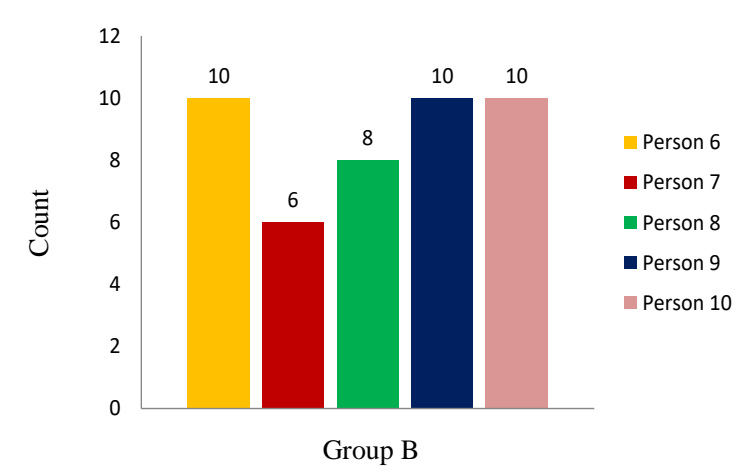

Figure 5. Histogram on correct identification by subject

Another observation was done to determine which braille codes were more distinct than the others. As shown in Table 1, the hijaiyah braille letters were characterised by the number and position of the raised dots. From the users' responses are as shown in Figure 6, the ض (dhod) and the ف (faa) braille letters were the most distinguished braille codes, followed by the letter s (yaa). The braille letters I (alif) and $\dot{\tau}$ (khaa) were the least correctly identified letters. It was initially perceived that the more number of raised dots for the braille letters, the higher the probability of a person to correctly identify a letter. However, this was not the case for the letter $\dot{\tau}$ (khaa), which has the same number of raised dots with ض (dhod) and $($ faa). Further tests will be required to identify the reasons for these findings.
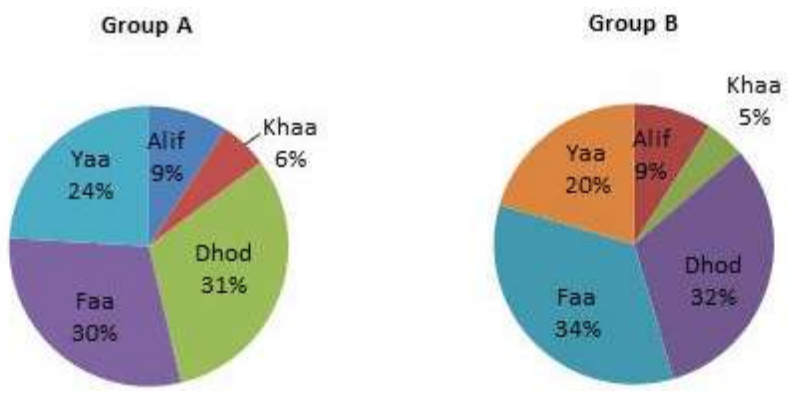

Figure 6. Pie chart of correct identification based on hijaiyyah braille letters for group A and group B

It is worth to note that the outcome of the psychophysical test may be affected by several factors. This was because the subjects of this test were not naturally blind or visually impaired person. The probability of the subjects having low tactile sensitivity was high as tactile was not the main stimuli and reflex in life.

Besides, these subjects were not familiar to rely on tactile-based device. If the braille module was tested on the new learner of visually impaired person the result might be slightly different. Though both of the subjects were new learner of Arabic braille code, however the non-visually impaired subject might encounter a hard time to distinguish the pattern of the braille code due to inability to reconfirm the pattern with visual. The visually impaired people are used to depend on surrounding object while sighted people lean on visual appearance. Moreover, the methods of perceiving information between the non-visually impaired 
people are also different from each other. Some person might use more tactile sense causing the tactile more sensitive than others.

There might some issues on the design of the frame/body of the braille module. Exact features measurement of the solenoid was not given by the manufacturer and all measurement was done using ruler in centimeter unit by a person. The body of the solenoid can be measured using the ruler however, the measurement of the valve tube were not accurate since it was not in a fixed position. Hence, the model of the braille module was not perfectly fitted with the arrangement of the solenoids. In addition, the frame of the braille module was printed using 3D printer technology might had physically and mechanical properties defect. The difference in the roughness of material increases the rate of friction between the solenoids and the braille module leads to unstable movement of the solenoids' valves.

\section{CONCLUSION}

A correct identification of $72.9 \%$ of the hijaiyyah braille letters show that the developed Arabic braille module, integrated with an open sourced mobile aplications and wirelessly controlled is capable in facilitating teaching and learning of Hijaiyah braille letters. Apart from low cost, the module is compact and light in weight to make it handy and portable to use. Furthermore, the modular design of the braille module means that it could be used not only for Arabic braille alphabets, but for other different alphabets and numerals. To increase the percentage of correct identification of the braille letters, the design could be made more compact, with narrower gaps between the six raised dots (miniature solenoids). Additional psychophysical tests could be conducted to see the users' responses to all hijaiyah braille letters to further conclude the percentage of correct identification.

\section{ACKNOWLEDGEMENTS}

This work was supported by the IIUM Research Initiative Grant Scheme (RIGS16-071-0235).

\section{REFERENCES}

[1] "Blindness and vision impairment prevention," World Health Organization, 2018. [Online]. Available: https://www.who.int/news-room/fact-sheets/detail/blindness-and-visual-impairment. [Accessed: 29-Jan-2019].

[2] Bourne RRA, Flaxman SR, Braithwaite T, Cicinelli MV, Das A, Jonas JB, et al.; "Vision Loss Expert Group. Magnitude, temporal trends, and projections of the global prevalence of blindness and distance and near vision impairment: a systematic review and meta-analysis". Lancet Glob Health, vol. 5, no. 9, pp. e888-97, 2017.

[3] Ryles, R., "The Impact of Braille Reading Skills on Employment, Income, Education, and Reading Habits". Journal of Visual Impairment \& Blindness, vol. 90, no. 3, p219, 1996.

[4] W. Elmannai and K. Elleithy, "Sensor-Based Assistive Devices for Visually-Impaired People: Current Status, Challenges, and Future Directions," Sensors, vol. 17, no. 3, p. 565, 2017.

[5] H. C. Wang, R. K. Katzschmann, S. Teng, B. Araki, L. Giarre, and D. Rus, "Enabling independent navigation for visually impaired people through a wearable vision-based feedback system," Proc. - IEEE Int. Conf. Robot. Autom., pp. 6533-6540, 2017.

[6] "Equipment for the Blind," OrCam, 2018. [Online]. Available: https://www.orcam.com/en/article/equipment-forthe-blind/. [Accessed: 11-Oct-2018].

[7] R. D. Fields, "Change in the Brain's White Matter: The role of the brain's white matter in active learning and memory may be underestimated," Science (80-. )., vol. 330, no. 6005, pp. 768-769, 2011.

[8] A. Bhattacharjee, A. J. Ye, J. A. Lisak, M. G. Vargas, D. Goldreich. "Vibrotactile Masking Experiments Reveal Accelerated Somatosensory Processing in Congenitally Blind Braille Readers". Journal of Neuroscience, vol. 30, no. 43 , pp. $14288,2010$.

[9] T. Mano and M. Ohka, "Mechanisms of fine surface texture discrimination in human," J. Accoust. Soc. Am., vol. 105, no. 4, pp 2485-2492, 1999.

[10] H. J. Kwon, W. L. Seok, and S. S. Lee, "Braille code display device with a PDMS membrane and thermopneumatic actuator," Proc. IEEE Int. Conf. Micro Electro Mech. Syst., pp. 527-530, 2008.

[11] P. Wagh, U. Prajapati, M. Shinde, P. Salunke, V. Chaskar, S. Telavane, and V. Yadav, "E-Braille-a self-learning Braille device," 2016 22nd Natl. Conf. Commun. NCC 2016, 2016.

[12] "Braille al-Qur'an learning (in Bahasa)," Pendidik, May 21, 2017. [Online]. Available: https://www.pendidik.com.my/2017/05/21/pembelajaran-al-quran-braille. [Accessed: 25-Jul-2019].

[13] Velázquez, R., Hernández, H., \& Preza, E.,. "A portable piezoelectric tactile terminal for Braille readers". Applied Bionics and Biomechanics, vol. 9, no. 1, pp. 45-60, 2012.

[14] Smithmaitrie, P., Kanjantoe, J., \& Tandayya, P. (2008). Touching force response of the piezoelectric Braille cell. Disability and Rehabilitation: Assistive Technology, vol. 3, no. 6, 360-365.

[15] M. Adnan, N. Dastagir, J. Jabin, A. Chowdhury, M. Rezaul, "A Cost Effective Electronic Braille for Visually Impaired Individuals”, 2017 IEEE Region 10 Humanitarian Technology Conference, pp. 21-23, 2017. 
[16] S. Gandhi, B. Thakker, and S. Jha, "Braille Cell Actuator Based Teaching System for Visually Impaired Students", IEEE International Conference on Recent Trends in Electronics, Information \& Communication Technology, pp. 1381-1385, 2016.

[17] Mohd Nor, A.Y., "Challenges in the Teaching and Learning of Braille al-Quran at the Malaysian Association for the Blind", Islamiyyat, vol. 38, no. 1, pp. 15-24, 2016.

[18] Norshidah Mohd. Salleh, Khadiijah Abd. Razak, and Noraini Mohd. Salleh. 2004. Teaching strategies of al-Quran among visually impaired students. Proceedings of the National Conference on Special Education, no. 2: pp. 452-463.

[19] D. S. Awang Damit, A. I. Che Ani, A. I. Muhamad, M. H. Abbas, and F. Z. Ali, "Dual braille code translator: Basic education tool for visually impaired children," I4CT 2014 - 1st Int. Conf. Comput. Commun. Control Technol. Proc., pp. 399-402, 2014.

[20] N. Amalia, "Android-based hijaiyah letter recognition application for refreshable braille display using melfrequency cepstrum coefficients and neural network (in Bahasa)," Institut Teknologi Sepuluh Nopember, 2017.

[21] A. Abualkishik and K. Omar, "Framework for translating the Holy Quran and its reciting rules to Braille code," Int. Conf. Res. Innov. Inf. Syst. ICRIIS, vol. 2013, pp. 380-385, 2013.

[22] A. Dasgupta, D. Seth, A. Ghosh, and A. Nath, "Real Time Sign Language to Braille Interfacing System," pp. 371-375, 2017.

[23] C. Moore and I. Murray, "An Electronic Design of a Low cost Braille Typewriter," in The Seventh Australian and New Zealand Intelligent Information Systems Conference, pp. 18-21, 2001.

[24] K. Kavitha, A. Priyadarshini, and V. Saradha, "Braille Teaching System for the Visually Impaired," in Second International Conference on Electronics, Communication and Aerospace Technology, pp. 1301-1304, 2018.

[25] N.A.Z. Nik Mohd Rahimi, N.H.H. Mohamad Hanif, Z. Janin, "Mobile Applications for Teaching and Learning Arabic Braille," 5th International Conference on Smart Instrumentation, Measurement and Applications, 2018.

\section{BIOGRAPHIES OF AUTHORS}

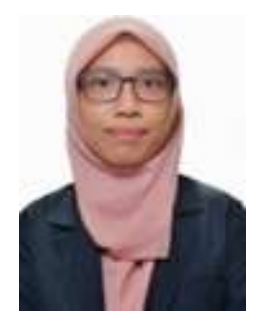

Nik Azimah Zainab Nik Mohd Rahimi has recently received B. Eng in Mechatronics Engineering from International Islamic University Malaysia in 2019. Her research interests include educational devices, artificial intelligence and robotics. She has been involved in robotic educational class for schoolers and college students.

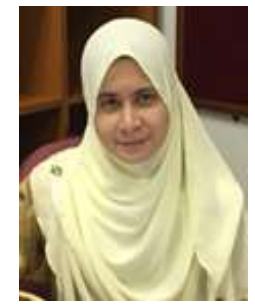

Noor Hazrin Hany Mohamad Hanif received her B. Eng (Hons.) from Universiti Teknologi PETRONAS, Malaysia in 2002 and completed her MSc in Control Systems from Imperial College, London, U.K., in 2004. She was awarded the $\mathrm{PhD}$ degree in Electronics \& Electrical Enginering from University of Southampton, U.K in 2016. She is currently an Assistant Professor at the Mechatronics Department, International Islamic University Malaysia. Her research interests include rehabilitation robotics, haptic technology, energy harvesting, wearable devices as well as instrumentation and control. Dr Hazrin is a Senior Member of IEEE, a member of the IET (Institution of Engineering and Technology) and Board of Engineers Malaysia (BEM).

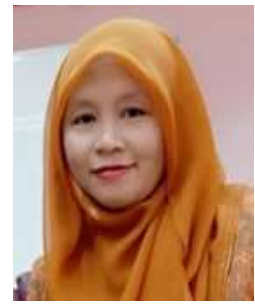

Zuriati Janin received her B.Eng in Electrical Engineering from the Universiti Teknologi Mara, Malaysia in 1996 and MSc. in Remote Sensing \& GIS from the Universiti Putra, Malaysia (UPM) in 2001. In 2007, she began her study towards a Ph.D in Instrumentation and Control System at the Universiti Teknologi Mara, Malaysia. She has served as a lecturer at Universiti Teknologi Mara for 20 years and currently she is a Senior Lecturer at Faculty of Electrical Engineering, UiTM, Shah Alam. Zuriati is an IEEE Senior Member (SMIEEE), IMS Member, IEM Companion Member (CIEM), ISA Member and SEEM Member. 